\title{
Underlying Dimensions and Organizational Values in Organizational Learning: Strategy for Capacity Building in Developing Countries
}

\author{
María Isabel Rivera Vargas
}

\begin{abstract}
The idea that organizational learning is closely linked to innovation became firmly established by the end of the nineties (Argyris and Schön, 1978; Watkins and Marsick, 1993; Nonaka and Takeuchi, 1995), however, very little research in these topics is done in developing countries. Therefore, the objective of this article is to expose the underlying dimensions as well as the organizational values that should characterize an organizational learning process, as a strategy for technological capacities construction in small and medium size firms. Consequently, through analytical-synthetic methodology including a case study analysis, this article evidence those determinants characteristics of an organizational learning approach to promote the planning of technological learning processes for catching up in order for developing countries to get into the path of innovation.
\end{abstract}

Keywords: organizational learning, innovation systems, technological learning, small and medium size firms, developing countries 


\section{Introduction:}

During the last decades it has been evident the crucial role that innovation play in the international market competition, which is based mainly on technological innovation, Therefore, it follows that scientific and technological capacity determines country export performance (Drucker, 1993; Reich, 1991; Castells \& Laserna, 1989). Thus, countries which innovation systems are not strong enough and consequently have not been traditionally great producers of technology or high technology products do not have any other option that to import both technology and high technology products.As a result, countries that need to import high technology products (both in capital goods and in consumer goods) see their balance of trade deteriorated in the same proportion that they have been forced to import and are unable to export high value added products. These conditions undermine the capacity of these countries to industrialize and develop. It is within this context that organizational learning becomes a key process, which adoption is imperative to plan a technological learning process and gradually reach innovation. According to several experts, scientific research in these topics has been concentrated mainly in advanced countries (Argyris and Schön, 1978; Von Hippel, 1988; Dodgson, 1993; Utterback, 1994; Nonaka and Takeuchi, 1995). The research in organizational learning and capacity building for technological development and innovation has received very little attention in developing countries. This is even though the extraordinary jump observed in some Asiatic countries, expressed in technological, educational and economic performance in which basis and foundation is found and organizational learning process; only many diplomatic visits and study trips to these nations, mainly by politicians and policy makers, but very little research in these topics has been done in countries trying to industrialize and develop, at least this is the case of Mexico. This is despite of the imperative need of theoretical models that capture organizational learning and technological advance in these countries as an important prerequisite to understand the dynamic process of capability building and inform policy makers for the design of suitable strategies for industrial advance.

Thereafter, the objective of this article is to expose the underlying dimensions as well as the organizational values affecting an organization's willingness to create and use said knowledge, characterized by the literature as learning orientation of organizational learning as a strategy for technological capacities construction.

Consequently, based on theoretical and empirical knowledge, including a case study analysis, this paper highlight the relevance of organizational learning for technological capacities construction and evidence the underlying dimensions, values and conditions that should be part of a suitable approach to promote the planning of technological learning processes for small and medium size firms in order to get into the path of innovation.

To develop this objective, after this introduction, in the first part it is depicted the theoretical and empirical literature that provides the foundations as well as explains and evidence the link between organizational learning and innovation, organizational learning and firm performance, as well as the underlying dimensions and organizational values that empirical research has demonstrated to have the major impact on organizational learning as an strategy for technological capacities construction. Once established the theoretical and empirical framework, in the second part, using and analytical-synthetic approach, it is presented as a case study The Technological Learning Model for catching up followed by newly industrialized Asian Countries. It will be analyzed the case study of the organizational learning process followed by Korean firms. The third part identifies and highlight the underlying dimensions and organizational values identified in this process, which coincide as well as support the results pointed out by several studies depicted in the analytical framework. As a result, those underlying dimensions and organizational values are proposed in the fourth part as some basis for the construction of a more suitable technological learning process for catching up in developing countries.

\section{I.Theoretical and Empirical Framework}

\section{Organizational Learning, Innovation, and Perfor- mance}

Organizational learning is supported as a construct that combines within a dynamic and spiral process of knowledge conversion from the individual and team level, that is individual and team tacit and explicit knowledge. The theoretical foundation advanced by Brown, Collins and Duguid (1989) supports learning in the context of the work by the individual at the moment, creating and authentic context for learning. They explain how individuals learn how to construct solutions to pressing organizational problems; while the theory of distributed cognition provides support for the organizational learning process at the team level.This theory sustains that cognition is distributed across individuals, and no one individual has complete knowledge as to how to accomplish a complex task (Salomon, 1996). In addition, Hutchins provides a very well documented example of distributed cognition in a work environment and affirm that cognition is distributed across the artifacts of an organization's work (1996). He explains that in a company environment artifacts are the knowledge products of the organization, these are the intermediate products of a larger process which could be design documents, quality plans, knowledge assets, blue 
prints, etc that document the organization's processes, instructions and expert advice.

The idea that organizational learning is closely linked to innovation became firmly established at the end of the nineties (Argyris and Schön, 1978; Watkins and Marsick, 1993; Nonaka and Takeuchi, 1995). Several authors have established that to meet the challenge of innovation, numerous organizations have opted to introduce the concept of organizational learning (Sinkula, 1994; Slater and Narver, 1995), which according to Baker and Sinkula (1999a), Ismail, (2005), Thomas and Alien, (2006), among others, it is a factor that enable organizations to respond in an expeditious way to market opportunities by helping to create the optimal innovation environment. Baker and Sinkula (1999b and 2002) have firmly demonstrated that organizations need organizational learning for the successful launch of new products or services into the market to meet consumer requirements and thus achieve enhanced performance and sustainable competitive advantage.

In sum, many authors coincide as to the positive link between organizational learning and innovation, among many others Hurley and Hult, 1998; Weerd-Nederhof et al., 2002; Ismail, 2005; even for nonprofits organizations some works have addressed the organizational learning - innovation connection. Additionally, Burt and Taylor (2003) as well as Voss et al., (2006) have examined the relation between innovation and performance, while others have been assessing the impact of organizational learning on performance (Grieves and Mathews, 1997; Zeilstra, 2003; Barrett et al., 2005).

With regard to the impact of organizational learning on performance, empirical works linking organizational learning to performance in for-profits organizations have traditionally established that greater the level of organizational learning better the performance, particularly in unstable settings involving strong competition. Specifically, it is posited that organizational learning might lead to a change in values (Argyris and Schön, 1978), skills (Fiol and Lyles, 1985), systems and structures (Levitt and March, 1988), innovation and competitiveness (Nason, 1994), financial performance (Lei et al., 1999; Pérez et al., 2005) and even employee satisfaction (Bontis et al., 2002).

For nonprofit organizations, in the area of public administration, Yim-Teo (2002) points out the socio-cultural and technical factors as two types of factors involved in organizational change. The findings from his study demonstrate that the socio-cultural aspects of change assume greater importance in environments in which learning is less apparent. In contrast, technical innovations are more in evidence where learning is greater. Studying the health service sector, Berta et al., (2005) state that adopting innovation is con- tingent upon the health institution's capacity to learn and transfer knowledge and to apply such knowledge in high quality decision-making. Also, McDonald (2002) have addressed in the nonprofit sector the mediating role of innovation between organizational learning and performance. For the same area of analysis in the health services McDonald (2007) feels that the goals which an organization aims to achieve and which are shared by all the employees will help new ideas to emerge and be assessed.

Although research in organizational learning has been concentrated in developed countries and it is scanty in developing countries, there are some studies in developing and new industrialized countries that also have been able to demonstrate how organizational learning contributes to build innovation capability and how this determines firm performance. Among these studies Salim, and Sulaiman, (20II), investigate the effect of organizational learning on innovation as well as the impact of innovation on company performance in the small and medium size firms of Information, Communication and Telecommunications Industry (ICT) in Malaysia. By analyzing 320 small and medium size enterprises operating in the ICT industry these authors found evidence that organizational learning contributes to innovation capability, and that innovation is positively related to firm performance.

\section{Underlying Dimensions of Organizational Learning Capability}

Chiva et al., (2007) identify five underlying dimensions of organizational learning capability: experimentation, risk taking, interaction with the external environment, dialogue and participative decision making as the most underlined facilitating factors for innovation in the literature. Among the arguments and evidence for the positive relationship to innovation of each factor are the following:

\section{Experimentation and Innovation}

Several authors have argued that management needs to encourage and support the freedom to conduct experiment with new work methods and innovative process (Senge, 1990; Garvin, 1993; Mcgill, Slocum and Lei 1992). Thomke (1998) contends that to ensure that technological implementation works, it often requires to do experimentation, using trial and error to find the solution. Lately, the same author declare that experimentation lies at the heart of every company's ability to innovate, and that new technologies reduce the cost and time of experimentation, allowing companies to be more innovative (Thomke, 200I). Beerkens (2004) found that companies that experiment novel technologies are better positioned to have a higher rate of innovation than firms that invest all their efforts in exploiting the 
existing familiar technologies. Precipe (2000) explains that experimentation allows to understand technological failure and to gain knowledge resulted from failure will be helpful for subsequent technology or product development. Thus, organizations can accelerate their innovations in effective way especially in new technology through experimenting new technology.

\section{Risk Taking and Innovation}

Several authors have conceptualized Risk-Taking as the organization's enthusiasm to break away from normal path and venture into unknown territory (Venkatraman, 1989; Wiklund and Shepherd, 2003). Liles (I98I) defines risk as the probability of an unconstructive result occurring from various courses of actions. Kouzes and Posner (1987) argue that learning from successes and mistakes resulted from risk taking will lead to increasing business opportunities. Saleh and Wang (1993) showed that innovative companies are more engaged in risk taking compare to less innovative companies. Peter and Waterman (1982) suggest that companies that are able to manage risk taking properly in their industrial context will achieve excellent results. But in addition, Hurley and Hult (1998) argue that Employees need support and collaboration among themselves to reduce fear and gain openness which encourages new risk taking. The willingness to take risk or risk taking will open great opportunity to firms in implementing technological innovations.

\section{Interaction with External Environment and Innovation}

External environment demands organization to be more cautious. The current trend in innovative firm which previously depended on internal $R$ and $D$, is highly working with external sources for the purpose of generating new product concept and building technology for product development (Chesbrough 2003). March, (1991) have argued that dependent on other sources of experience is important for firm with new product to successfully explore new ways to compete. Cyert and March (1963) contend that an organization needs to deal with external shocks, in turn they must adapt and learn to cope with that situation during their whole life. Varis and Littunen (20I0) showed that external sources of information are positively associated with the introduction of novel product innovations in firms. It has been demonstrated that organizations need to establish relationships with external entities including customers, competitors, universities, or government agencies etc. Such collaboration will bring benefits to the firms including the latest changes or developments which affect firms.

\section{Dialogue and Innovation}

Most scholars and practitioners of organizational learning conceive the process of dialogue as to provide an avenue for communication and collaborative learning within and between groups and teams (Isaacs, 1993; Schein, 1993). In agreement to that, Gear et al., (2003) sustain that in organizational studies, dialogue has become important as an aspect of understanding the difficulties and possibilities of learning and change. Supporting these statements, Balthasar et al., (2000) found that successful technological innovation is positively influenced by individuals communication. Other studies have conclude that the process of inter-functional coordination promotes communication, collaboration, cohesiveness, trust and commitment among different functional areas (Auh and Menguc, 2005) and the extent of product innovation ( Zhang and Yanling, 2010). Frederick (2005) stresses that development of new product is a complex process requiring cross-functional involvement from beginning through the end, in other words, throughout the process. Song and Parry (1992) consider the integration level as a critical determinant of new product performance. Thus, the role of dialogue among organizational members can produce better understanding by sharing meaning on related issues and speeding in sharing information.

\section{Participative Decision Making and Innovation}

The decision making process plays an important role in the success of product innovation process (Kok and Creemers, 2008). Moreover, participative decision making increases commitment and involvement, but also has a positive impact in innovation (Damanpour, 1991). Brown (1979) has recommended that when a firm is experiencing a major technological change, the use of participative decision making is the main priority mechanism. Wall and Lischeron (1977) explain that the increase in participation during decision making will result in less resistance to change and better possibility for adoption of new technology. Bahrami and Evans (1987) have found that successful high technology firms practice decentralized decision-making and high degree of participation by line managers in decision-making when dealing with changes in the environment. Furthermore, according to West and Anderson (1996) the ability to participate in decision making is a key process in enhancing innovation. Therefore, Ahmed Fadzil, (200I) concludes that participative decision making is the most essential factor to favor technological innovation.

Using these five underlying dimensions of organizational learning proposed by Chivas, et al., (2007), briefly described above, Mat and Che Razak (20II) explore the relationship between organizational learning capability and their impact on success of technological product innovation implementa- 
tion.To analyze this relationship they design a cross-sectional study that involves a correlational empirical methodology for the purpose of testing the relationship between the independent, moderating and dependent variables. They used self administered questionnaires and received $I I 5$ responses from electrical and electronics (E\&E) firms in Malaysia.These authors demonstrate that there is a significant relationship between three of the five underlying dimensions proposed by Chivas, et al., (2007), the significant dimensions on success of technological product innovation and implementation are: participative decision making, interaction with external environment and risk taking.

In addition to that, Nonaka (1994) and Nonaka \&Takeuchi (1995) have identified Leadership and creative chaos as two organizational factors affecting formal and informal processes and structures that facilitate organizational learning, and definitely confirm that leadership is strongly related to risk taking.

\section{Learning Orientation and Innovation}

According to Nevis et al., (1995) learning orientation determines the way organizations acquire, share and utilize knowledge. It might emphasize knowledge source, productprocess focus, documentation mode, dissemination mode, learning focus, value-chain focus, or skill development focus. Sinkula et al., (1997), advance the concept of learning orientation and defines it as a series of organizational values affecting an organization's willingness to create and use said knowledge. These organizational values that conform the learning orientation concept are considered as an indirect measure of organizational learning. These organizational values are according to Sinkula et al : commitment to learn, open mind and shared vision. They define these values as follows: commitment to learn as closely linked to a managerial commitment to support a culture which promotes organizational learning as one of its core values.An open mind involves questioning the preconceived ideas or assumptions that shape the acts of the organization's members, thus enabling the incorporation of new ideas and points of view and adding life-long learning. This will in turn further and improve individual knowledge, and help create a shared vision or common notion of what the organization should be in the medium and long term. In other words, the board shares its perception of the organization's future with all the junior levels (1997). However, other authors have pointed out a fourth value to this concept of learning orientation, this is: intra-organizational knowledge sharing, advanced by Calantone et al., (2002) and conceived as the various types of information accumulated through knowledge learned by or spreading across different departments that will be advantageous to experiences and lessons shared by all units and saved in an organization's memories or mutual understand- ing between departments for any improved integral concept of one enterprise.

Using these four organizational values Chiou, and Chen (20I2) investigate relationships among learning orientation, innovation capital and firm performance in Taiwan's Information, Telecommunications and Electronic industry. By using Structural Equation Modeling (SEM) and conceptualizing financial performance as measured return on assets, return on investments and profitability, these authors analyzed a sample of 317 listed companies from this industry. Chiou and Chen's study demonstrates that three out of the four organizational values of learning orientation defined above such as open-mindedness, shared vision and intra-organizational knowledge sharing except commitment to learning, have a positive effect on innovation capital; understanding Innovation capital as the capability to create products, services or processes possessed by an enterprise which includes explicit intelligent properties (Bass and Van Buren, 1999) or implicit R\&D abilities such as internal research and development (Edvisson and Malone, 1997). In addition to that, these authors also found that the innovation capital has a positive effect on firm performance. In other words, as the source of innovation capital, having a learning orientation within firms, it is positively related to firm performance.

Also, Garrido and Camarero (2010) analyzed the relationship between learning orientation, innovation and performance for the case of 386 British, French and Spanish museums. Concurring with the literature which links learning orientation to organizational performance, these authors found that learning orientation is reflected in enhanced financial and social performance. Their study confirms that learning orientation determines the implementation of organizational innovations although the effect is noticeably higher for large museums than for small ones. Thus, the influence of learning orientation on technological innovation, is also confirmed. This study confirms that organizational innovation affects mainly technological innovation and, to a lesser extent, product innovation. As regards the impact of innovation on financial performance, the findings of these authors show significant differences depending on the size of the museum. However, they mention that while technological innovation does have a positive impact on financial performance for all kinds of museum, organizational innovation only affects performance in the case of small museums, whereas product innovation only influences financial performance in large museums.

Lately other scholars have been exploring the link between learning orientation and innovation (Yim-Teo, 2002; Berta et al.., 2005; McDonnald, 2007). In the area of public administration, Yim-Teo (2002) points out to the socio-cultural and technical factors as two types of factors involved in 
organizational change. The findings from his study demonstrate that the socio-cultural aspects of change assume greater importance in environments in which learning is less apparent. In contrast, technical innovations are more in evidence where learning is greater. Studying the health service sector, Berta et al., (2005) state that adopting innovation is contingent upon the health institution's capacity to learn and transfer knowledge and to apply such knowledge in high quality decision-making. In the nonprofit sector McDonald (2002) have addressed the mediating role of innovation between organizational learning and performance. In the health services McDonald (2007) found that the goals which an organization aims to achieve and which are shared by all the employees will help new ideas to emerge and be assessed.

In services marketing literature, several works demonstrate that any technological improvement needs an organizational adaptation. Damanpour and Evan (1984) explain this point with the case of a bank that offers a new service requiring a new set of administrative mechanisms to evaluate and control its performance. They show that administrative innovations oblige technical innovations. Also $\mathrm{Han}$ et al., (1998), using banking industry data, reveal a synergistic relationship between technical and administrative innovations.

In Mexico there are a few studies about technological learning process. Among them could be cited the study of Alonso, Carrillo and Contreras (2002), which describe and analyze how some firms from Asia and United States, established in Tijuana have become more competitive, as a result of technological learning process by adopting flexible productive and organizational strategies. Contreras and Munguía (2007) analyze the evolution of the industrialization model of 'maquiladoras' emphasizing the technological learning process and industrialization in the north part of the country, but more than a study about an organizational learning process, it focus on the description of the evolution of industrialization in that part of the country. Other authors such as Contreras and Carrillo (201I) have analyzed if Multinational Corporations (MNC) established in Mexico have promoted technological learning in the suppliers network, however their study have been no conclusive.

Moreover, the Korean organizational learning process for capacity building described by Kim's study (1998) is a living case confirming the highly important role played by each one of the underlying dimensions and learning orientation values analyzed above. Most of the five underlying dimensions of organizational learning as well as the four organizational values that characterize learning orientation analyzed in the literature, just depicted, and pointed out as factors highly promoting innovation could be identified in the Korean organizational learning process. This Korean process represents an extraordinary jump expressed in technological, educational and economic performance in Korea, and therefore it is a suitable case to be analyzed in the following section.

\section{Case Study Analysis}

\section{The Korean Technological Learning Process}

According to Kim's description (1998) the Korean technological learning process for catching up exhibits a learning orientation characterized by different and subsequent learning focus such as duplicative imitation, creative imitation and innovation. Beginning from the assimilation of assembly operations, all these four subsequent phases were fed by the assimilation of foreign technology. Therefore, at the heart of the Korean catching up process could be identified an organizational learning process, enriched by national innovation systems' interactions, particularly with MNCs through which Korean firms engage in assembly operations. This is the case of Hyundai, Samsung and more than two hundred firms in different industries - not just electronics (Kim, 1980), but also automobiles (Kim, 1998), semiconductors (Kim, 1997), shipbuilding (Amsdem, 1989; Kim, 1985), iron (Amsdem, 1989; Amsdem and Kim, 1985), and machinery (Amsdem and Kim, 1986). Firms in all these different industries followed a similar expeditious learning pattern for catching up based on a process of organizational learning. Using the case of Hyundai, as described by Kim (1998), the following section depicts this technological learning process for catching up in its subsequent phases and identifies the underlying dimensions and values, which important role in organizational learning is being analysed here.

Kim analyzes very closely and reports how the first three subsequent learning stages were based and achieved through learning by doing and learning by using foreign packaged and unpackaged technology, while the innovation stage was achieved through learning by research, after the company have become proficient in the three previous phases.

Hyundai's technological learning process shows how it was nourished constantly and permanently through its interactions with international innovation systems at all stages of development achieved. Hyundai began by assimilating mature technologies from developed countries, especially through contract agreements with MNCs. Without previous experience in automobile production, Hyundai assimilate and improve packaged and unpackaged technology through learning by doing and learning by using, the mastering of these capacities enabled Hyundai to challenge more advanced technologies and progressively be able to learn by research and attain innovation. Hyundai develops its technological learning process mainly going through the mastering of more simple to more sophisticated capabilities, such as, acquisitive 
capability, operative capability, adaptive capability and finally, innovative capability; capacities which in Kim's conceptual framework were described as the mastering of operative capacity, duplicative imitation, creative imitation and innovation, which could be equivalent and also represent stages going from the simpler to the more complex or from minor to major level of understanding in the technologies it was dealing with as Dahlman \& Westphal (1983, p.7) as well as Shiowattana (1991) classify them. Therefore, the depiction of the technological learning process followed by Hyundai as described by Kim (1998) shows how first, it acquires operative capability, then, on the basis of the former it acquires duplicative imitation capacity, once the imitation capacity was mastered, its absorptive capacity and prior knowledge base developed provided a platform for the third stage, during which it gains creative imitation capacity, and finally all that prior knowledge base developed provided the platform to learn by research and achieve innovative capacity. All of those learning stages were based on an organizational learning process, which was structured by forming taskforce groups with team members from Hyundai' several divisions according to background and specialties required, as well as from outside auto producers with more experience in automobile production.

These taskforces teams began the first phase in the organizational learning process described here: assimilation of assembly operations in 1967 without any experience in automobile production ( Kim, 1998). Subsequently these teams were through the second, third and fourth phase of the organizational learning process. During the process of acquiring the first three capacities Hyundai increases its absorptive capacity to assimilate technology mainly through learning by doing and learning by using relying on different sources of explicit knowledge provided by technology suppliers such as technical specifications, production manuals, blue prints, received with the acquisition of packaged and unpackaged technology, but also increasingly by research on international literature reviews.

The company was able to convert this explicit knowledge gained into tacit knowledge by organizing study groups by task and objective and promoting an expeditious organizational learning process with the help of specific training and specific visit tours offered by technology providers, or by foreign experts with previous work experience in multinationals car producers, and expatriates with doctoral degrees earned at United States Universities. This expeditious organizational learning process was enhanced with organizational strategies fed by all the organizational values and underlying dimensions pointed out by the literature discussed here from which outstands sociocultural factors such as proactively constructed crisis and intensity of efforts. The first, were primarily team crises with focus and clear goals, which intensify the efforts among organizational members to expedite learning, elevating the absorptive capacity of the organization, and therefore, turning crisis into opportunities. The second, materialized by working sixteen hours a day, seven days per week. These organizational strategies were present in every of the four stages of the Korean organizational learning process reported here, which sometimes were exacerbated by externally evoked crisis and therefore increasing even further the intensity of efforts to convert explicit into tacit knowledge; to translate tacit to explicit knowledge; and also for the translation of tacit to tacit knowledge (socialization) as well as to the translation of explicit knowledge to explicit knowledge (combination of discrete pieces of knowledge into a new whole, according to Nonaka, 1994 and Nonaka and Takeuchi, 1995).

The externally evoked crisis were mainly originated in government demands, market turbulence, and technological barriers. For example, during the second stage of the process Hyundai faced a major crises coming from the government radical demand to shift from assembly production of foreign cars to the development of locally designed Korean cars. The crisis from the market was faced during the third stage due to rising gasoline prices and falling car sales that demand Hyundai to manufacture a car to meet the most stringent safety and environmental requirements to compete in the North American market. The technological barrier crisis, faced at the fourth stage of its learning process, provide the conditions and accelerated Hyundai's process of learning by research to achieve innovation. This external crisis of technological nature consisted of a technology barrier imposed by technology providers, which prompted Hyundai to reach innovation capacity through learning by research relying on its international research and development network (R\&D) that it had begun to build step by step since 1978, but it was not until 1984 when it began to materialize with the establishment of the Advanced Engineering and Research Institute, created to develop its own engines and transmissions (Kim, 1998).

The learning process examined here shows that prior knowledge base developed and registered during and at the end of each phase increased the absorptive capacity of Hyundai providing a platform for the succeeding phase while representing an increase in its absorptive capacity. That is to say, that the mastery of operative, duplicative and creative imitation capacities served as prior knowledge base to reach innovation capacity at Hyundai.

Going beyond the organization boundary, it is absolutely important to point out that in addition to the development of the organizational learning process as a whole within the organization boundary, there is evidence of systemic planning efforts beyond that frontier.These are expressed in the 
Government provision of incentives in the form of protection barriers and promotion plans for strategic industries. Specifically, the strategic industrial plans, coordinated by the government, which design anticipated market, technological and governmental impacts, as well as external factors and conditions such as: protection of the local market from new entrants and from new foreign knock-down imports, a significant tax reduction, promotion of vertical integration leading to new business opportunities, preferential financing, tax concessions and administrative decree to guarantee a large market share for the indigenous Korean car model demanded by the government. There was confluence in all the industrial plans, which were conducted, coordinated and focused to reach the great goal established for the Nation State, to industrialize and develop through the acquisition of technological capability. In addition, the systemic planning efforts involved in this technological learning process can be detected in the congruence and convergence of the industrial, educational as well as science \& technology policies issued and coordinated by the government inter alia, the investment in R\&D, education and human resource development all directed to support the organizational learning process for catching up at the technological level.Thus, the role played by the Korean government as promoter of the systemic planning, mentioned above, which in the case of Korea was a crucial strategy and part of a more ambitious government goal to orchestrate industrialization. The government was in charge, not only to design, but also to coordinate the industrial, economic, educational, scientific and technological public policies issuing the corresponding programs and mechanisms to support this learning effort by providing scholarships for studies abroad in strategic areas demanded by the technological learning process for catching up. That is the government played a crucial function by creating the conditions and providing the resources to build the educational platform, to provide the training and the scientific research required by the industrialization process and by the society as a whole. In addition, the government was also a great promoter of collaborative and coordinated relations between universities and research institutes with the industrial sector. Furthermore, the government assure the collaboration and coordination that the promotion plans in strategic industries demanded.

\section{Analysis of the Korean Organizational Learning Process}

Most of the underlying dimensions and organizational values pointed out by the literature, as determinants for and organizational learning process such as experimentation, risk taking, interaction with the external environment, dialogue, participative decision making as well as organizational values such as commitment to learn, open mind, shared vision, intra-organizational knowledge sharing can be identified in this organizational learning process which in turn supports the results pointed out by empirical research depicted in the first section.

Experimentation and Risk Taking, these two dimension have characterized all the four phases of Hyundai's organizational learning process. Along the first phase, it could be appreciated the experimentation and risk taking in trying to assimilate and dominate the assembly operations in car production through the process of learning by doing and learning by using, without previous experience in car production. In the second phase the experimentation and risk taking is materialized in trying to produce the first Korean car through the process of learning by doing and learning by using achieving imitation by duplication. This is also the case of the third and fourth phase, when Hyundai experiment trying to manufacture a car capable of meet the most stringent and safety demands to compete in the North American Market through creative imitation and when Hyundai took the risk and experiment in manufacturing the first subcompact car designed on its own through research, respectively.

The interaction with the external environment is evident in all the four phases of the organizational learning process. On the one hand, with the international innovation systems interactions through which Hyundai obtained packaged and unpackaged technology, consultants, professional experts, international literature, etc. More specifically with multinational corporations, universities, research centers, government, etc. On the other hand, Hyundai faced government demands, market demands and technological barriers.

Dialogue and Participative Decision Making are two underlying organizational dimensions that could be appreciated in the internal dynamic of the different taskforces organized with internal and external human resources for the purpose of achieving specific goals along the fourth stages of the organizational learning process.

Organizational values such as commitment to learn, open mind, shared vision and intraorganizational knowledge sharing were present along the four stages of the organizational learning process, otherwise, the achievements show in each stage and specifically the acquisition of innovation capability could not be possible.

This is congruent with McDonald (2007) proposition that the goals which an organization aims to achieve and which are shared by all the employees will help new ideas to emerge and be assessed.

Closely related to those underlying organizational dimensions and values pointed out, it is important to underline the Far Sighted and Risk-Taking Leadership and Entrepreneur- 
ship that characterize the adoption and accomplishment of this expeditious learning processes undertook by Hyundai, as Kim (1998) reports and Kirk identifies as crucial in the investment ventures implicated in the process (1994). Without any doubt this process implies a great deal of experimentation, risk taking, strong interaction with the external environment as all the process through the four stages was nourished by the interaction with International Innovation Systems. But, also this characteristic has been recognized in other chaebols or Korean Industrial groups such as those in electronics, semiconductors, shipbuilding, and machinery industries, which have followed the same expeditious learning process for catching up, as it has been documented by Kim and Amsdem, among other authors, as cited earlier.

Another very important factor identified by $\mathrm{Kim}$ (1998) in this catching up process undertook by Hyundai is the Proactively Constructed Crisis, or Creative Chaos, as the works of Nonaka (1994) and Nonaka and Takeuchi (1995) define it. Kim reports proactively constructed crisis in every phase of this technological learning process. The description demonstrates how in each phase proactively constructed crisis leads to an increase in intensity of effort. Supporting the latter it is mentioned an idiosyncratic feature such as the hard work habit of Koreans, expressed in the 16 hours work a day, seven days per week, as registered by Kim (1997, 1998). That is, this intensity of effort reported was possible because of this Korean habit of hard work, which in turn finds its roots in socio-cultural characteristics, supporting Yim-Teo (2002) affirmation that the socio-cultural factors are involved in organizational change. But in addition, these organizational factors could not be successfully helping in the achievement of the objectives targeted in each stage without the presence of organizational values such as commitment to learn, open mind, shared vision and intraorganizational knowledge sharing.

As a result of the systemic planning identified as a one of the crucial factors of this unique Korean learning process, just pointed out, it is important to register the availability of well-trained Human Resources, as very relevant and indispensable factor. According to the United Nations report, Korea is the only country within the developing category that made a double jump - from low to medium and from medium to high level in terms of the human development index between 1960 and 1992 (United Nations Development Program, 1994). In addition, the number of scientists and engineers per 10,000 population is the highest among the developing countries and closer to that of developed countries such as France and United Kingdom (Ministry of Science and Technology, 1994). The Korean evidences of human resource development are not easy to match and undoubtedly requires a long-term investment in education, science and technology infrastructure, nutrition, health, housing, and security, among others.
The analysis of this process also points out that the pattern followed concentrate all its efforts first in the strength of Production \& Engineering capacity, achieved during the first and second stage of the process, when Hyundai complete capabilities in duplicative imitation materialized in the first Korean manufactured car. After that, as a second step, the emphasis was in achieving creative imitation, that is - to achieve some Development, materialized in the produced Korean car that was able to meet the safety conditions demanded to compete in the North American Market. And it was not until the subsequent stage, when Hyundai accomplish capacities for Research \& Innovation. That is, the Korean process reverse the sequence in the traditional pattern promoted by national and international innovation systems, institutions, organisms and policy makers in developing countries to promote and achieve innovation: Research-Development-Engineering (R-D-E), which is the pattern adopted in developed countries e historically imposed by the science and technology institutions as conventional pattern to promote and achieve innovation in developing countries. IV. Conclusion: Basis for the Design of a Technological learning process for catching up in developing countries.

As a conclusion, we have strong evidence about the effectiveness of some basic factors for the design of a technological learning process for catching up in developing countries. Without any doubt, the underlying dimensions as well as the organizational values that characterize the learning orientation in the Korean organizational learning process analysed here with the case of Hyundai were crucial and determined the successful process of industrialization in that country. Therefore, all of those factors should be taking into account when thinking in the design of an organizational learning process for catching up in developing countries. But, besides the strong recommendation for inclusion of those organizational dimensions and values in an organizational learning process, this study strongly emphasize the importance of systemic planning and also propose the convenience to reverse the sequence in the traditional pattern Research-DevelopmentEngineering (R-D-E), which is the pattern adopted in developed countries e historically imposed by the science and technology institutions as conventional pattern to promote and achieve innovation in developing countries. This proposal is based on the successful experiences in Korea and other South-East Asian countries, which experiences have been shown here as a result of the analytical-synthetic approach applied to the case of Hyundai. Therefore, instead of focusing financial resources and efforts to achieve Research (R), then develop some prototypes, $(D)$; and produce and engineer them, $(E)$. The proposed path to follow is to strength production and engineering capacities (E) first, then try to creatively imitate some products, (D); so that the capacity for research and innovation (R\&l) could be attained over the basis of the mastering of less sophisticated 
capacities.Thus, the proposal is to promote a process mainly going through the mastering of more simple to more sophisticated capabilities, thus, acquiring first, acquisitive capability, operative capability, adaptive capability and innovative capability; capacities which in Kim's conceptual framework were described as the mastering of operative capacity, duplicative imitation, creative imitation and innovation, that is to reverse the pattern R-D-E and follow the pattern E-D-R, which is a model that has demonstrated major suitability and effectiveness for capacity building, and catching up specifically for developing countries which economies are dominantly characterized by small and medium size firms.

\section{References}

ARGYRIS, C. and Schön, D. (1978). Organzational Learning: A theory of Action Persective. Reading, MA:Addison-Wesley Publishing Company

AHMAD Fadzil, N.F. (200I). Structural, cultural values and innovation, Unpublished MBA Theses, Schoool of Management, Universiti Sains Malaysia, Penang.

AHUJA, G., 2000. Collaboration Networks, Structural Holes and Innovation:

ALONSO, J. Carrillo, J. and Contreras, O. (2002), Aprendizaje tecnológico en las maquiladoras del norte de México, Frontera Norte, 14 ( 27), 43-82.

AUH, S. and Menguc, B. (2005). Top management team diversity and innovativeness: the moderating role of interfunctional coordination. Industrial Marketing Management, 34(3), 249-26I.

AUSBEL, D. et al. (I983). Psicología Educativa. México: Ed. Trillas.

AMSDEM, A. (1989). Asia's next giant: South Korea and late industrialization. New York: Oxford University Press.

AMSDEM, A. 2004. 'Import substitution in high-tech industries: Prebisch lives in Asia!' CEPAL, Review, 82 (April), 7791.

AMSDEM, A. and L. Kim. (1985). 'The acquisition of technological capability in

Korean industries'. World Bank, mimeograph.

and 1986. 'Technological perspective on the general machinery industry in the Republic of Korea'. In Machinery and economic development, ed. Martín Fransman, 93-123. London: Macmillan Press.
BAHRAMI, H. and Evans, S. (1987). Stratocracy in hightechnology firms. California Management Review, 30, 5I-66.

BAKER, W. and Sinkula, J. (1999a). The synergistic effect of market orientation and learning orientation on organizational performance. Journal of Academy of Marketing Science 27 (4) 4 I I-427.

BAKER, W. and Sinkula, J. (1999b), Learning Orientation, Market Orientation, and Innovation: Integrating and Extending Models of Organizational Performance. Journal of Market Focused Management, 4, 295-308 http://dx.doi. org/ 10.1 I 77/ 0092070399274002

BAKER,W. and Sinkula, J. (2002). Market orientation, learning orientation and product innovation: delving into the organization's black box. Journal of Market-Focused Management, 5, 5-23.

BALTHASAR, A. Batting, C. and Wilhelm, B. (2000). Developers-key actors of the innovation process. Types of developers and their contacts to institution involved in research and development, continuing education and training and transfer of technology, Technovation, I4(2), 523-269.

BARRET, H. Balloun, J. Weinstein, A. (2005). The impact of creativity on performance in non-profitts. International Journal of Nonprofit and Voluntary Sector Marketing, 10 (4), 213-223.

BASSI, L. and Van Buren, M. (1999). Valuing investment in intellectual capital. International Journal of Technology Management, I8 ( 5/6/7/8), 4I4-432.

BEERKENS, B. (2004). External acquisition of technology: exploration and exploitation in international innovation. Eindhoven University Press, Unpublished Phd Thesis.

BERTA, W., Teare, G., Gilbarte, E., et al.( 2005). The contingents of organizational learning in long term care: Factors that affect innovation adoption. Health Care Management Review, 30 (4), 282-292.

BONTIS, N., Crossan, M. and Hulland, J. (2002). Managing an organizational learning system by aligning stocks and flows. Journal of Management Studies, 39 (4), 437-469

BROWN, B. (1979). Academic Libraries: an Operation Model for Participation. Canadian Library Journal, 36, 20 I-207.

BROWN, J. S., Collins, A. and Duguid, P. (1989) Situated cognition and the culture of learning. Educational Researcher, I8(I), 32-42. 
BURT, E. and Taylor, J. (2003). News Technologies in embedded values, and strategic change: evidence from U.K. voluntary Sector. Nonprofit and Voluntary Sector Quarterly, 32 (I), II5-127

CALONTONE, R., Cavusgil, S., \& Zhao, Y. (2002). Learning orientation, firm innovation capability, and firm performance. Industrial Marketing Management, 3I (6), pp. 5I 5-524. http:// dx.doi.org/I0.1016/S0019-850I(0I)00203-6

CASTELLS, M. and Laserna, R. 1989. 'The new dependency: Technological change and socioeconomic restructuring in Latin America'. Sociological Forum, 4 (4).

CHESBROUGH, H., (2003). Open Innovation:The New Imperative for Creating and Profiting from Technology. Cambridge, MA.: Harvard Business School Press,

CHIVA, R., J.Alegre and R. Lapiedra, 2007. Measuring organizational learning capability among the workforce, International Journal of Manpower, 28(3/4), 224-242.

$\mathrm{CHIOU}$, and Chen (20I2) Relations among Learning Orientation, Innovation Capital and Firm Performance: An Empirical Study in Taiwan's IT/Electronic Industry. International Journal of Management 29 (3) Part 2 (September), 321332

CONTRERAS and Munguía (2007) Maquiladoras, aprendizaje tecnológico y política industrial en el norte del país, Economía Informa, IIE-UNAM, 352, (mayo-junio), I 27-I 46.

CONTRERAS, O. and Carrillo, J. (20II) "Las empresas multinacionales como vehículos para el aprendizaje y la innovación de las empresas locales". en Bracamontes, A. y O. Contreras (coord.), Ciencia, Tecnología e Innovación, El Colegio de Sonora, 325-354.

CYERT, R.M. and March, J. G. (1963).A Behavioral Theory of the Firm. 2nd ed. Englewood Cliffs, N.J.: Prentice Hall

DAHLMAN, C. and Westphal, I. (1983). 'The transfer of technology: Issues in the acquisition of technological capability by developing countries' Finance and Development, 20 (December), 6-9.

DAMANPOUR, F and Evan,W. (1984) Organizational Innovation and Performance:The problem of Organizational Lag. Administrative Science Quarterly, 29 (3), 392-4I0

DAMANPOUR, F. (I99I). Organizational innovation: a metaanalysis of effects of determinants and moderators,Academy of Management Journal, 34(3), 555-590.
DODGSON, M. 1993. 'Organizacional learning: A review of some literature' Organization Studies, I4, 3 375-394

DRUCKER, P. 1993. Post capitalist society. New York: Harper Business A division of Harper Collins Publishers.

EDVISSON, L., and Malone, M. (1997). Intellectual capital: Realizing your company's true value by finding its hidden roots. New York: Harper Collins Publishers, Inc.

FIOL, M., and Lyles, M. (1985). Organizational Learning. Academy of Management Review, I0(4), 803-8I3.

FREDERICK, S. (2005). Cognitive Reflection and Decision Making. Journal of Economic Perspectives, 19(4), Fall, 24-42.

GARVIN, D.A. ( 1993). Building a learning organization, Harvard Business Review, 7 I (4), 78-9I.

GEAR, T.Vince, R. Read, M. and Minkes, A. L. (2003). Group enquiry for collective learning in organizations. Journal of Management Development, 22(2), 88- 102.

GRIEVES, I. and Mathews, B. (1997). Healthcare and the learning service. The Learning Organization, 4 (3), 88-97.

HAN J. Kim, N. Srivastava, R. (1998). Market orientation and organizational performance: is innovation a missing link? Journal of Marketing, 62, 30-45.

HURLEY, R. and Hult, G. (1998). Innovation, market orientation, and organizational learning: an integration and empirical examination. Journal of Marketing, 62, 42-54.

HUTCHINS, E. (1996). Cognition in the wild. Cambridge: MIT press.

ISAACS, W. (1993). Dialogue, collective thinking and organizational learning. Organizational Dynamics, 22(2), 24-39.

ISMAIL, M. (2005). Creative climate and learning organization factos: their contribution towards innovation. Leadership \& Organization Development Journal 26, (7/8), 639-654.

KIM, L. 1980.'Stages of development of industrial technology in a developing country: A model'. Research Policy 9 (July): 254-277.

1985.'Innovation in a newly industrializing country:A multiple discriminate analysis'. Management Science 3 I (3): 312-322.

1997.'The dynamics of Samsung's technological learning in semiconductors'. California Management Review, 39 (3), 86-100. 
. 1998. 'Crisis construction and organizational learning: Capability building

in catching-up at Hyundai Motor'. Organization Science, 9 (4), 506-52I.

KIRK, D. 1994. Korean dynasty: Hyundai and Chung Ju Yung. Armonk, NY: M. E. Sharpe.

KOK, A.W. and Creemers, P. A. (2008). Creemers Alliance governance and product innovation project decision making. European Journal of Innovation Management. I I (4), 472-48.

KOUZES, J.P. and. Posner, B. Z. (1987). The Leadership Challenge: How to get extraordinary things done in organizations. San Francisco: Jossey-Bass

LEI, D., Slocum, J., Pitts, R. ( 1999). Designing organizations for competitive advantage: the power of unlearning and learning. Organizational Dynamics, 37 (3), 24-38

LEVITT, B. and March,J. (1988). Organizational learning. Annual Review of Sociology, I4, 319-340.

LILES, P.R. (198I). Who are the entrepreneurs?. In P. Gorb, P. Dowell and P.Wilson (eds). Small Business Perspectives. London:Armstrong Publishing, London Business School,: 3350.

MARCH, J.G. (199I). Exploration and exploitation in organizational learning. Organization Science, 2, 7I-87.

MAT,A. and Che Razak, R. (20I I) Empirical Research on The Relationship Between Organizational learning Capability and Success of Technological Product Innovation Implementation In Electrical and Electronics Sector. Australian Journal of Basic and Applied Sciences, 5 (I I), 730-738.

MCDONALD, R. (2002). Knowledge entrepreneurship: Linking organizational learning and innovation. University of Connecticut.

MCDONNALD, R. (2007). An investigation of innovation in nonprofit organizations: the role of organizational mission. Nonprofit and Voluntary Sector Quarterly, 36 (2), 256-28I.

MCGILL, W., Slocum, D. andLei, D. (1992). Management Practice in Learning Organization. Organizational Dynamics, $21(1), 5-17$.

MINISTRY of Science and Technology, Korea (MOST) 1994. 1994 Report on the Survey of Research and Development in Science and Technology. Seoul: MOST, 75
NASON, R. (1994). Globalization and macromarketing. Journal of Macromarketing, I4 (2), I

NONAKA, I. 1988. 'Creating organizational order out of chaos: Self renewal in Japanese firms'. California Management Review 30 (3): 57-73.

(1994). A dynamic theory of organizational knowledge creation. Organization Science, 5(I), I4-37.

NONAKA, I. and Takeuchi, H. (1995). The knowledge creating company. New York: Oxford University Press.

PÉREZ, S. Montes, J. Vázquez, C. (2005). Organizacional learning as determining factor in business performance. The Learning Organization, 12 (3), 227-245.

PETERS, T. and Waterman, R. (1982). In search of excellence: Lesson from America's best run companies. New York: Harper and Row.

PORTER, M.E. 1990. The Competitive Advantage of Nations, Free Press, New York, NY.

PRECIPE, A. (2000). Breadth and depth of technological capabilities: in CoPS; The case of the Aircraft Engine Control System. Journal of Research Policy, 29, 895-91I.

REICH, R. 1991. The work of nations: Preparing ourselves for the 2 I st Century Capitalism. New York:Alfred A. Knopf.

SALEH, S.D. and Wang, C.K. (1993). The Management of Innovation: Strategy, Structure and Organizational Climate. IEEE Transactions on Engineering Management, 40, I3-2I.

SALIM, I. and Sulaiman, M. (20I I). Organizational Learning, Innovation and Performance:A Study of Malaysian Small and Medium Sized Enterprises. International Journal of Business and Management, 6 (12) (December), II8-126

SALOMON, G. (1996). Distributed Cognitions. Cambridge: Camb ridge University Press.

SCHEIN, E.H. (1993). On dialogue, culture, and organizational learning, Organizational Dynamics, 22(2), 40-5I. 737

SENGE, P. (1990). The leader's new work: Building learning organization. Sloan management review, Fall, 7-23.

SHIOWATTANA, P. I99I Technology transfer by Thailand's electronic industry. In S. Yamashita (Ed.). Transfer of Japanese technology and management in the ASEAN countries. Tokio, Japan: University of Tokyo Press. 
SINKULA, I. (1994). Market information processing and organizational learning. Journal of Marketing, 58 (I), 35-45.

SINKULA, J., Baker, W., \& Noordewier, T. (1997). A framework for market-based Organizational Learning: Linking values, knowledge and behavior. Journal of the Academy of Marketing Science, 25, 305-3I8.

SCHON, D. 1967. Technology and change:The new Heraclitus. Oxford: Pergamon.

SLATER, S. and Narver, J. (1995). Market orientation and the learning organization. Journal of Marketing, 59, 63-74.

SONG, X.M. and Parry, M. E. (1992).The R\&D- marketing interface in Japanese high-technology firms. Journal of Product Innovation Management, 9(2), 9I-II2.

THOMAS, K. and Alien, S. (2006). The learning organization: a meta-analysis of themes in literature. The Learning Organization, 13 (2/3), I23-140.

THOMKE, S. (1998). Managing experimentation in the design of new products. Journal of Management Science, 44, 743762.

(200I). Enlightened experimentation:The new imperative for innovation. Harvard Business Review, 79, 6775.

UNITED Nations Development Program. 1994. Human resource development report, 1994. New York: Oxford University Press.

UTTERBACK, J. 1994. Mastering the dynamics of innovation: How companies can seize opportunities in the face of technological change. Boston: Harvard Business School Press.

VARIS, M. and Littunen, H. (20I0). Types of innovation, sources of information and performance in entrepreneurial SMEs. European Journal of Innovation Management, 13(2), 128154.

VENKATRAMAN, N. (1989). The concept of fit in strategy research: toward verbal and statistical correspondence, Academy of management review, 9, 513-525.

VON HIPPEL, E. 1988. The sources of innovation. New York: Oxford University Press.

VOSS, G. Montoya-Weiss, M. and Voss, Z. (2006). Aligning innovation with market characteristics in the nonprofit professional theater industry. Journal of Marketing Research, 43, 296-302.
WALL, T.D. and Lischeron, J. H. (1977). Worker Participation:A Critique of the Literature and Some Fresh Evidence. Maidenhead, U.K.: McGraw- Hill,

WATKINS, K. and Marsick, V. (1993). Sculpting the Learning Organization. San Francisco: Jossey-Mass

WEERD-Nederhof, P. Pacitti, B., Da Silva, J. Pearson,A. (2002). Tools for the improvement of organizational learning processes in innovation. Journal of Workplace Learning, 14 (8), 320-331.

WEST, M.A. and Anderson, N. R. (1996). Innovation in top management teams. Journal of Applied Psychology, 8I, 680693.

WIKLUND, J. and Shepherd, D. (2003). Knowledge-Based Resources, Entrepreneurial Orientation and the Performance of Small and Medium-Sized Businesses. Strategic Management Journal, 24, I307-I3 I4.

YIM-TEO, T. (2002). Learning organization a cultural breakthrough in the public sector. The Journal of Applied Management and Entrepreneurship, 7 (3), 48-7I.

ZEILSTRA, D. (2003). Reciprocal learning in teams: relational practices for securing the best from leadership volunteers in nonprofit organizations. Unpublished PhD dissertation. Case Western Reserve University Weatherhead, School of Management.

ZHANG, J. and Duan, Y. (20I0). Empirical study on the impact of market orientation and innovation orientation on new product performance of Chinese manufacturers Nankai Business Review International, I (2), 2I4-23I. 